\title{
Financeirização, empresas não financeiras e o ciclo econômico recente da economia brasileira *
}

\author{
Mariana Finello Corrêa ${ }^{\text {** }}$ \\ Pedro de Medeiros Lemos ** \\ Carmem Feijo ${ }^{* * * *}$
}

\begin{abstract}
Resumo
Este artigo analisa as mudanças nas estratégias patrimoniais das empresas não-financeiras ao longo dos anos 2000 com base na literatura sobre financeirização e ciclo financeiro de Minsky. A análise empírica mostra que a repercussão interna da crise financeira internacional de 2008 resultou em um aumento na fragilidade financeira das empresas não financeiras (ENFs), o que explica em grande parte o quadro recessivo atual. A contribuição do artigo é mostrar a adequação da hipótese da fragilidade financeira de Minsky para explicar a reversão do ciclo expansivo de investimento observado em meado dos anos 2000 e como avança o processo de financeirização na economia brasileira.
\end{abstract}

Palavras-chave: Financeirização; Economia brasileira; Ciclo Minskyano; Empresas não-financeiras; Investimento.

\begin{abstract}
Financialization, non-financial corporations and the recent economic cycle in the Brazilian economy.

This paper analyzes the changes in the equity strategies of non-financial corporations during the 2000s based on the literature on financialization and Minsky's financial fragility hypothesis. The empirical analysis shows that internal repercussions of the 2008 international financial crisis resulted in an increase in the financial fragility of non-financial corporations, which largely explains the current recession. The contribution of the paper is to show the appropriateness of Minsky's financial fragility hypothesis to explain the reversal of the expansionary investment cycle observed in the mid-2000s and the process of financialization in the Brazilian economy.
\end{abstract}

Keywords: Financialization; Brazilian economy; Minsky’s cycle; Nonfinancial firms; Investment. JEL E12, E44, G01.

\section{Introdução}

O processo de financeirização das economias modernas tem sido descrito na literatura econômica por diferentes correntes do pensamento heterodoxo, como

* Artigo recebido em 27 de março de 2017 e aprovado em 18 de setembro de 2017. Os autores agradecem os comentários do parecerista que muito contribuíram para o aperfeiçoamento do trabalho. Eventuais falhas que ainda persistam são de responsabilidade dos autores.

** Doutoranda de Economia na Universidade Federal Fluminense (UFF), Niterói, RJ, Brasil. E-mail: finello.mari@gmail.com.

${ }^{* * *}$ Mestrando de Economia na UFF, Niterói, RJ, Brasil. E-mail: pedropedroml@ hotmail.com.

${ }^{* * * *}$ Professora Titular na UFF / Pesquisadora do Conselho Nacional de Desenvolvimento Científico e Tecnológico (CNPq), Niterói, RJ, Brasil. E-mail: cbfeijo@gmail.com. 
por exemplo pós-keynesiana, marxista, institucionalista e regulacionista ${ }^{1}$. Epstein (2005) define a financeirização pelo aumento da importância dos mercados, das instituições e dos atores financeiros para as transações econômicas. Essa caracterização apresenta a vantagem de ser genérica o suficiente para descrever distintas realidades e backgrounds históricos, econômicos e sociais.

Bonizzi (2013) destaca que o fenômeno da financeirização para as economias em desenvolvimento apresenta especificidades em relação às economias desenvolvidas. Nessas economias, o fenômeno da financeirização é, em geral, associado à liberalização e à desregulamentação financeira, e dessa maneira esse fenômeno é considerado externally driven (Karwowski; Stockhammer, 2017, p. 63) ${ }^{2}$. Ou seja, a financeirização nas economias em desenvolvimento tem como fator determinante a sua integração subordinada ao mercado financeiro global ${ }^{3}$.

Karwowski e Stockhammer (2017, p. 61) identificam seis interpretações do fenômeno da financeirização para as economias em desenvolvimento, dentre as quais destacamos a liberalização da conta capital e financeira, a integração dessas economias com o mercado financeiro global $^{4}$, e a elevação do nível de endividamento das empresas não financeiras (ENFs) ${ }^{5}$. Os autores também destacam que a última interpretação pode dar margem para a ocorrência de outro sintoma do fenômeno da financeirização: a queda dos gastos de investimento por parte das ENFs, que tende a deprimir a taxa de crescimento do produto a longo prazo.

Em se tratando da economia brasileira, de acordo com Bruno e Caffé (2015, p. 52), o processo de financeirização apresentou particularidades em relação a outras

(1) Outros termos são utilizados como sinônimos de financeirização na literatura econômica. Como por exemplo: finance-led growth regime (Boyer, 2000), financial wealth-induced growth regime (Aglietta, 2000), finance-dominated capitalism (Hein, 2012), shareholder value orientation (Stockhammer, 2005-2006), maximizing shareholder value (Lazonick e O'Sullivan, 2000); financial neoliberalism (Palley, 2013) ou financeled capitalim (Guttmann, 2016).

(2) Condicionantes internos dos países também influenciam o fenômeno da financeirização, de maneira que ele não inteiramente externally driven.

(3) Powell (2013, p. 3) define a subordinação como: "Subordinate financialisation involves the subjugation of domestic monetary policies to the imperatives of international capital; the turn of domestic corporations to global markets requiring engagement in derivatives, the assumption of market risk and the surrender of profits to foreign investors; and debt financed consumption by an elite who seek to hold their wealth in world money".

(4) Painceira (2009) argumenta que o Plano Brady, no início da década de 1990, pode ser considerado o início do processo de liberalização financeira nas economias latino-americanas e, em particular, na economia brasileira. Sicsú (2006) apresenta uma descrição das mudanças nas regras do mercado de câmbio doméstico no Brasil na década de 2000 com o objetivo de fazer avançar na integração financeira do país. Ver também Biancarelli (2010) e Carneiro (1999), entre outros.

(5) As seis interpretações identificadas por Karwowski e Stockhammer (2017, p. 61) são: a desregulamentação e a integração financeira dessas economias no sistema financeiro global como fomentadores da financeirização (1), os fluxos financeiros internacionais como força motora desse fenômeno (2), liberalização financeira incentivando a ocorrência de uma inflação de preços dos ativos (3), a mudança de um sistema financeiro baseado em bancos para um baseado no mercado de capitais (4), aumento do nível de endividamento das empresas (5) e a maior participação das famílias no mercado financeiro e também seu maior endividamento (6). 
economias em desenvolvimento. Os autores observaram que antes mesmo do processo de desregulamentação e abertura financeira e comercial era possível constatar acumulação rentista-financeira via ganhos inflacionários. Esta, por sua vez, seria a primeira fase do processo de financeirização da economia brasileira, denominada pelos autores de "hiperinflação". Ela engloba os anos entre 1970 e 1993. A segunda fase do processo de financeirização iniciou-se após a estabilização monetária proporcionada pelo Plano Real. Uma vez que os ganhos inflacionários não mais se verificavam, a acumulação rentista-financeira se direcionou para os ganhos através dos juros. Os autores denominam essa fase de "hiperjuros"6. Desta forma, para os autores, a financeirização da economia brasileira não foi iniciada com o processo de desregulamentação e abertura comercial e financeira. Porém, esse processo impulsionou o aprofundamento da financeirização na economia brasileira e inaugurou uma nova fase desse fenômeno.

Pari passu ao processo de liberalização financeira observou-se no Brasil a perda da autonomia da política econômica e a redução do espaço de política fiscal para promover o investimento na infraestrutura econômica e social. Kregel (2000) descreve esse processo de perda de autonomia como um círculo vicioso particular dado os níveis historicamente elevados das taxas de juros domésticas. Quando ocorre a liberalização financeira a tendência é que o diferencial de juros seja mantido positivo com o objetivo de atrair capital. O movimento de capital, por sua vez, segue o ciclo financeiro das economias desenvolvidas. Os influxos de capital em excesso causam a apreciação da taxa de câmbio e o aumento do déficit do governo através das operações de esterilização. A escassez de liquidez internacional, por outro lado, leva a economia a ajustar a taxa de juros para cima, pressionando o câmbio. Neste contexto, o autor destaca que a única opção que as autoridades econômicas têm para compensar o círculo vicioso de elevação da taxa de juros e de apreciação cambial exige manter os gastos públicos contraídos. A contração de despesas governamentais, combinada com as altas taxas de juros, implica manter a demanda interna em nível baixo, o que gera uma menor taxa de crescimento e uma pressão para aumento da dívida pública ${ }^{7}$.

(6) Após a estabilização monetária via Plano Real, a economia brasileira caracterizou-se pela utilização de altas taxas de juros, o que possibilitou que a acumulação rentista-financeira se centrasse nos ganhos com as taxas de juros. A liberalização das contas de capital e financeira implicou manter níveis de taxas de juros básicas elevados para atrair capitais. Como a maior atração é por capitais de curto-prazo, seu impacto é o de aumentar a volatilidade do câmbio, manter a taxa apreciada tornando a economia mais vulnerável a choques externos. Os altos níveis de taxa de juros também aumentam a rentabilidade dos ativos financeiros, especialmente dos títulos da dívida pública federal pós-fixados que são indexados às taxas de juros de curto-prazo (Bruno et al., 2011).

(7) Kregel (op. cit.) sugere que uma alternativa para o rompimento deste círculo vicioso é a gestão da política econômica com o objetivo de desenvolver instrumentos que possibilitem a ampliação do espaço de política. Esse rompimento possibilitaria em uma mudança na estrutura produtiva, tornando-a mais sofisticada tecnologicamente e competitiva em âmbito internacional. 
Desde a abertura econômica, processo iniciado na segunda metade da década de 1980, a economia brasileira apresentou um cenário macroeconômico favorável contínuo apenas no período 2003-2008, crescendo em média 4,2\% a.a. Este crescimento ocorreu em um cenário externo favorável que permitiu a geração de consecutivos superávits na conta corrente, um afluxo de capital estrangeiro estável e inflação sob controle ${ }^{8}$. Ou seja, durante esse período foi observado um momento de superação parcial da "era de instabilidade macroeconômica" observada desde a década de 1980 (Bielschowsky; Mussi, 2006, p. 34). Contudo, esse período de superação foi abruptamente interrompido pela crise financeira internacional em 2008. Entre os anos de 2009 e 2016, o desempenho do PIB foi oscilante e com tendência de desaceleração, refletindo em grande medida a incerteza externa e, a partir de 2015, a incerteza decorrente da crise política. Desde 2015, a economia brasileira se retrai, acumulando um decréscimo de 7,2\% entre 2015 e 2016. A contribuição deste trabalho é na direção de explicar por que a economia brasileira apresenta uma retração tão acentuada desde 2015. A hipótese deste artigo é que a crise financeira iniciada na economia americana em 2007 alterou os cenários macroeconômicos externo e interno, impactando negativamente as decisões de investimento em ativos fixos e afetando as estratégias patrimoniais dos bancos e das ENFs. Como seria esperado, estas estratégias se tornaram mais defensivas ${ }^{9}$, dado o cenário de baixo crescimento e elevada incerteza sobre as possibilidades de retomada do ritmo de crescimento econômico. Por outro lado, o aprofundamento do processo de financeirização da economia brasileira desde a abertura econômica abriu novas possibilidades de acumulação de riqueza, contribuindo para alterar o comportamento de bancos e empresas. Concluímos que a presente crise da economia brasileira se configura como uma crise de caráter minskyniano, sendo que sua superação só ocorrerá quando a capacidade de acumulação de capital das firmas não-financeiras for recuperada, assim como o grau de confiança nas expectativas para induzir o investimento em ativos de capital. Para a realização dessa análise, utilizaremos a conexão da literatura sobre financeirização e o aparato teórico desenvolvido por Minsky (1986).

Este artigo está dividido em mais quatro seções além dessa introdução. A segunda seção apresenta a discussão teórica sobre financeirização dentro do escopo teórico do ciclo econômico de Minsky. A terceira seção é dedicada a discutir as características do crescimento da economia brasileira nos anos 2000. Na quarta

(8) O aumento do espaço de política ocorreu na economia brasileira, e nas economias em desenvolvimento em geral, no período 2003-2007, como apontam Karwowski e Stockhammer (op. cit.). Neste período, o crescimento mundial liderado pela China também veio acompanhado de um aumento expressivo dos fluxos financeiros internacionais, em especial dirigidos às economias em desenvolvimento. Os autores destacam que a intensificação desses fluxos é uma dimensão internacional da financeirização.

(9) Isto é, uma estratégia caracterizada por uma a preferência pela liquidez mais elevada. 
seção será analisado o financiamento e o comportamento das ENFs. A última seção apresenta a conclusão do trabalho.

\section{Financeirização e o ciclo econômico de Minsky}

Mesmo que existam especificidades nos processos de financeirização nas diferentes economias, as dinâmicas desse processo nas economias norte-americana e inglesa servem como norte para a análise desse processo (Karwowski; Stockhammer, 2017). Uma dinâmica observada nessas economias e identificada como possível sinal do fenômeno da financeirização pela literatura é o aumento do nível do endividamento das ENFs. A importância do aumento do endividamento se expressa nos possíveis impactos negativos sobre os gastos de investimento dessas empresas (Stockhammer, 2004; Karwowski; Stockhammer, 2017; Orhangazi; $2008)^{10}$.

O aparato teórico desenvolvido por Minsky $(1986,1992)$ sobre posturas de financiamento das empresas e a vulnerabilidade financeira é essencial para conectar o fenômeno da financeirização ao nível da firma e seus efeitos sobre o investimento produtivo e a instabilidade econômica.

A hipótese da instabilidade financeira (HIF) de Minsky $(1986,1992)$ foi desenvolvida para um ambiente econômico com um sistema financeiro sofisticado e complexo e que, se validada, produz momentos alternados de estabilidade e turbulência econômica. Estes movimentos, tanto de bonança como os de instabilidade, seriam decorrentes das reações racionais dos agentes econômicos na defesa de sua riqueza. A inter-relação desses agentes em momentos de otimismo pode ocasionar oscilações nos preços dos ativos e bolhas especulativas. A presença de bolhas especulativas antecede momentos de reversão do ciclo econômico que levam à recessão. Desta forma, a principal conclusão do modelo de Minsky, sob a HIF, é que economias de mercado não tendem ao equilíbrio. Neste contexto, a intervenção de políticas públicas é decisiva tanto para evitar a formação de bolhas especulativas como para amenizar as consequências da reversão do ciclo econômico sobre os níveis de produção e emprego agregados.

O processo de financeirização nas economias em desenvolvimento está relacionado com a integração financeira global e com a redução da regulamentação dos fluxos de capital. Este movimento foi intensificado a partir das décadas de 1980 e 1990. Ele permitiu que investidores (empresários, especuladores e banqueiros) fizessem aquisições nos mais variados setores e países, impulsionados por um

(10) Financialisation could have negative effects on investment in real assets through two channels. First, increased financial investments could have a negative effect by crowding out real investment and creating shorttermism; second, increased payments to financial markets can constrain real investment by depleting internal funds, shortening planning horizons and increasing uncertainty (Orhangazi, 2008, p. 865). 
otimismo que nascera da crescente desregulamentação dos mercados financeiros acoplado com as mudanças tecnológicas.

O significativo desenvolvimento do sistema financeiro mundial trouxe consigo novos métodos de acumulação de capital. Outrora, o sistema capitalista tinha como padrão a acumulação de riqueza proveniente das vendas de bens e serviços que seguiam a seguinte dinâmica: o empresário do setor não financeiro investia seus recursos ${ }^{11} \mathrm{em}$ ativos de capital para a produção de bens que possuíam expectativa de demanda positiva. Com suas expectativas confirmadas, ao vender os seus produtos realizavam lucros que remuneravam o capital investido anteriormente. Com a crescente modernização do sistema financeiro e consequente ascensão e sofisticação da oferta de seus produtos e serviços, a acumulação de capital assume novas formas. As oportunidades de investimento não se restringem a aplicações potencialmente rentáveis na acumulação de capital com geração de emprego e renda a nível agregado, e ampliam-se para aplicações mais líquidas, em títulos financeiros (que oferecem, além do retorno financeiro, a possibilidade de valorização). Ou seja, os ativos financeiros atendem aos critérios de oferecer rentabilidade e liquidez, reduzindo o grau de incerteza envolvido no processo de acumulação de capital em ativos fixos. Desta forma, a crescente financeirização das economias modernas permite que a geração de riqueza ocorra, pelo menos por um período de tempo, sob a forma de acumulação de ativos que não geram renda e emprego a nível agregado.

Boyer (2000) ilustra bem o contexto das transformações nas inter-relações entre grupos de agentes econômicos provocados pela crescente financeirização ao fazer uma clara distinção entre dois tipos de regime de crescimento: um regime induzido pela acumulação de capital - conhecido como "fordismo" e outro regime de crescimento orientado pela financeirização - finance-led growth regime. Neste último caso, o aumento da produtividade do trabalho não é mais um alvo estratégico para a empresa não financeira. Segundo ele, num regime de crescimento liderado pelas finanças, o que importa é a rentabilidade financeira da empresa, independentemente de isso ser alcançado por meio de um rápido crescimento da produtividade, aumento da eficiência da força de trabalho ou rendas oligopolísticas decorrentes da inovação (op. cit., p. 123). A abordagem da financeirização implica que a acumulação de riqueza não se limita à expansão do estoque de capital produtivo, mas também à acumulação de uma cesta diversificada de ativos combinando capital produtivo e financeiro. Tanto mais a valorização da riqueza agregada for o resultado do aumento da acumulação de ativos financeiros, as taxas

(11) Nesse sentido o crédito possui um papel fundamental. Os banqueiros negociam com os empresários as regras para o empréstimo. Nesta negociação os empresários apresentam propostas com elevado grau de expectativa de ganhos futuros e os banqueiros, de maneira natural, são mais céticos em relação à proposta que está sendo negociada. Ou seja, pode-se dizer que o sistema capitalista une os períodos (passado presente futuro) através das relações financeiras (Minsky, 1992). 
agregadas de renda e crescimento do produto serão baixas e as preferências de liquidez e as taxas de juros tenderão a ser altas ${ }^{12}$.

A razão disso é que, num contexto de financeirização, as decisões que envolvem um longo período de tempo acabam dependendo principalmente de decisões tomadas por empresas financeiras para expandir financiamentos a fim de atender a demanda por aquisição de bens de capital ou para reverter o peso acumulado de dívidas ${ }^{13}$. Isto implica assumir que, uma deterioração das expectativas implicará uma redução na oferta de novos empréstimos, absolutamente ou, mais provavelmente, em termos relativos, elevando as taxas de juros. Esta reação visa evitar a erosão das margens de segurança nos empréstimos. Nesse sentido, a demanda agregada é contraída, mas não necessariamente a parcela da renda auferida pelo setor financeiro. Na verdade, no regime de crescimento liderado pelas finanças, a parcela de renda ganha pelos proprietários de riqueza tenderia a aumentar independentemente do ritmo de crescimento econômico. Em períodos de expectativa otimista, um volume maior de empréstimos garantiria o rendimento das empresas financeiras e em períodos de deterioração das expectativas, as taxas de juros aumentariam quando o volume de crédito fosse reduzido e a taxa de crescimento desacelerasse. Este papel especial das empresas financeiras na acumulação de capital permite ao setor financeiro aumentar sua participação na renda total, aumentando a riqueza financeira, apesar da desaceleração da taxa de crescimento da renda agregada e da produção.

Todavia, a HIF é uma teoria que mostra os impactos que as dívidas exercem sobre o comportamento das empresas e consequentemente sobre toda a economia. Ou seja, na HIF as flutuações econômicas são decorrentes da forma como as empresas financiam seus investimentos. Dentro da seara dos financiamentos é possível encontrar diferentes tipos de posição financeira, e quanto mais vulnerável está uma economia, maiores são as chances de ocorrer o processo de instabilidade financeira, pois o número de unidades excessivamente endividadas em relação à geração de renda é elevado. E, consequentemente, o excesso de endividamento das empresas afeta negativamente os seus gastos com investimento.

De modo geral, o momento de instabilidade ocorre quando os agentes estão sem a liquidez necessária para efetuar o pagamento das suas obrigações. A fim de não entrar em uma posição de default pela falta de liquidez, os empresários tentam vender seus ativos em regime de urgência. Dessa maneira, a tendência é que o ativo

(12) Além disso, num contexto de integração financeira dos mercados de capitais internacionais e taxas de câmbio flexíveis, as oportunidades de especulação são intensificadas.

(13) O aumento da importância dos meios externos de financiamento também está ligado ao processo de financeirização através das alterações na governança coorporativa das empresas via aumento do shareholder value. Os trabalhos dessa literatura destacam a existência de dois principais canais de transmissão do aumento do poder dos acionistas vis-à-vis os executivos: via preferências e via meios internos de financiamento (Hein, 2012, p. 2). 
seja vendido abaixo do preço de mercado, enquanto na contramão deste movimento, os agentes com liquidez se recusam a demandar tais ativos enquanto estes exibirem uma tendência de baixa nos preços. Nesse sentido fica exposto o que Minsky (1992) chamou de "debt-deflation feeds upon debt-deflation" $"$.

Em relação ao financiamento para os seus investimentos em um momento de elevada expectativa e baixa incerteza, os agentes podem contar com a renda esperada da sua produção e com os rendimentos provenientes dos juros de aplicações financeiras. Podem contar também com o financiamento externo através da emissão de ações, venda de ativos ou simplesmente através de empréstimos financeiros concedidos pelos bancos.

Tomados pelo otimismo de um mercado que apresenta viés de crescimento, os investidores se endividam a fim de conseguirem vantagens investindo em ativos financeiros e de capital cujos rendimentos esperados sejam suficientes para cobrir todo o passivo adquirido. Este grupo de investidores encontra-se em uma posição denominada de hedge, ou seja, estão em uma posição, a priori, na qual não dependem de novos financiamentos para liquidar suas dívidas. Isto é, o passivo pode ser financiado pelo fluxo de caixa ou estoque de capital.

Outros investidores que possuem mais entusiasmo com a expectativa de alta do mercado podem subestimar a capacidade de reversão do cenário econômico. Desta forma os investidores adotam uma postura menos avessa ao risco, ou seja, investem de maneira mais agressiva. Em uma posição financeira chamada de especulativa, os agentes tomam empréstimos que, por vezes, só conseguem liquidar, com os seus rendimentos realizados, os juros e uma pequena parte do passivo, contudo, mantém a maior parte do montante inicial das obrigações. Este grupo necessita de novo financiamento para poder refinanciar a dívida. Os especuladores, de um modo geral, possuem a expectativa que no longo prazo os lucros esperados sejam capazes de cobrir suas obrigações financeiras cuja tendência seria de redução ao longo do tempo.

Em se tratando da fragilidade financeira, a posição mais agressiva e que possivelmente incita a instabilidade é a posição Ponzi. Nesta posição os investidores não conseguem, com o seu fluxo de caixa ou com o estoque de ativos, sequer efetuar os pagamentos dos juros da dívida, de maneira que é necessário efetuar outros empréstimos para liquidar a dívida já existente. No caso da posição Ponzi a dívida é crescente e tende a ser insustentável no médio e no longo prazo.

(14) Neste processo de compra e venda de ativos, ressalta-se que, na maioria das vezes, o ativo mais rentável possui maior risco e menor liquidez. Ou seja, são estes, que por sua vez, sofrem pressões inflacionárias por excesso de entusiasmo (especulativo) dos agentes. Outro destaque deve ser feito para negociações efetuadas com juros flutuantes, esta característica traz consigo certa vulnerabilidade inclusive para os investidores na posição hedge. 
Quanto maior for o número de empresas em posição especulativa e Ponzi, mais o cenário macroeconômico estará sujeito à instabilidade financeira. Quando uma economia encontra-se nessas condições, qualquer choque mais acentuado, como por exemplo, uma elevação da taxa de juros, pode deflagrar uma crise. Ressalta-se que o mercado é extremamente dinâmico de maneira que não é possível prever todas as incertezas do futuro. Com isso tem-se que os agentes conseguem mudar o posicionamento financeiro ao longo do tempo.

Em suma, a teoria de Minsky (1986, 1992) complementa a literatura existente sobre financeirização, principalmente na análise deste fenômeno no plano da empresa, ao definir as posturas financeiras possíveis para as empresas e sua conexão com o ciclo econômico.

\section{A economia brasileira nos anos 2000: a liderança da formação de capital}

Avaliando o desempenho da economia brasileira nos últimos vinte e um anos (Tabela 1), é possível destacar o período entre 2004-2010, que incorpora as maiores taxas médias de crescimento econômico (4,5\%). Esse período foi caracterizado por condições externas favoráveis (liquidez internacional e boom dos preços das commodities) e expansão do consumo doméstico. Dentre os componentes da demanda agregada, o destaque recai sobre a formação bruta de capital fixo (FBCF), que teve um crescimento médio no período de $8,2 \%{ }^{15}$.

Tabela 1

Taxas de crescimento médias ao ano do PIB, e componentes da agregada: períodos selecionados (em \%)

\begin{tabular}{c|c|c|c|c|c|c}
\hline & PIB & $\begin{array}{c}\text { Consumo } \\
\text { Famílias }\end{array}$ & $\begin{array}{c}\text { Consumo } \\
\text { Governo }\end{array}$ & $\begin{array}{c}\text { Formação } \\
\text { Bruta de } \\
\text { Capital Fixo }\end{array}$ & Exportação & Importação \\
\hline $1996-2003$ & 2,0 & 1,4 & 1,5 & 0,2 & 7,6 & 0,7 \\
\hline $2004-2010$ & 4,5 & 5,3 & 3,2 & 8,2 & 5,4 & 14,0 \\
\hline $2011-2014$ & 2,4 & 3,5 & 1,7 & 2,3 & 1,6 & 3,9 \\
\hline $2015-2016$ & $-3,7$ & $-4,1$ & $-0,8$ & $-12,0$ & 4,1 & $-12,2$ \\
\hline
\end{tabular}

Fonte: SCNT (IBGE). Elaboração própria.

A aceleração da taxa de crescimento foi induzida pelo cenário externo favorável e foi ampliada pelas políticas econômicas implementadas no período. Neste cenário, tem-se a elevação do consumo e dos investimentos privado e público. Os investimentos foram beneficiados tanto pelo boom de exportações, como pela elevação do consumo. Este último foi impulsionado pela melhora na distribuição de

(15) Destaca-se ainda que no período compreendido entre 2004 e 2010 a taxa de investimento não foi maior devido ao "vazamento de parte da demanda de máquinas e equipamentos e insumos intermediários para o exterior, em razão da especialização regressiva” sofrida pela indústria nacional (Carneiro, 2017, p. 3). 
renda (via política de valorização do salário mínimo e via política de transferência de renda), aumento nas taxas de emprego e elevação da oferta de crédito ao consumidor.

O Gráfico 1 mostra a evolução das taxas de crescimento do PIB e da FBCF no período 1996-2016. Esses dados corroboram a interpretação que o crescimento do período destacado anteriormente foi liderado pela $\mathrm{FBCF}^{16}$. Principalmente, a partir do segundo semestre de 2006, pois verifica-se uma quase sobreposição das duas séries, indicando que o crescimento do PIB segue a evolução da FBCF.

\section{Gráfico 1}

Taxa acumulada em quatro trimestres em relação ao mesmo período do ano anterior (\%)- 1996-2016

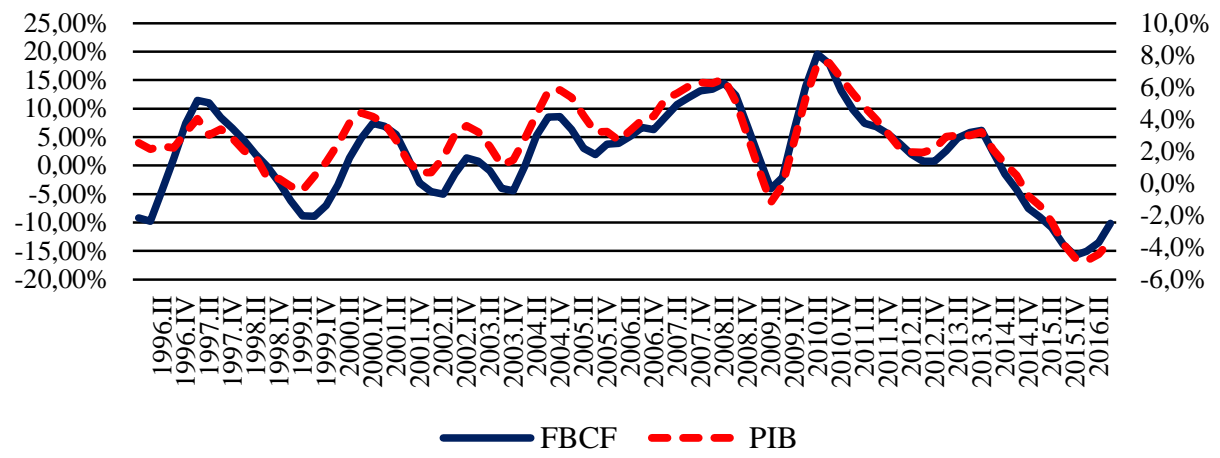

Fonte: SCNT (IBGE). Elaboração própria.

É interessante notar que a evolução da FBCF segue a queda no PIB em 2009, ano em que a contração da demanda mundial e o colapso dos preços das commodities atingem a economia brasileira, que se retraiu em $0,1 \%{ }^{17}$. A queda observada na taxa de crescimento da FBCF ocorreu no segundo semestre de 2009.

(16) Uma primeira fase, que compreende os anos entre 1996-2003 também pode ser destacada a partir da tabela 1. Nesse período, a taxas de expansão do PIB foram de 2,0\% em média ao ano e a política macroeconômica focou na estabilização dos preços. Desde a estabilização de preços com o plano Real, ocorreram sucessivos choques externos: em 1994 a crise mexicana, em 1997 a crise asiática, em 1998 a crise russa. Além disso, em 2001 a economia brasileira sofreu uma grave crise de energia elétrica e em 2002 o país enfrentou fuga de capitais como resultado de expectativas negativas pelos mercados em relação à eleição presidencial de um candidato com viés nacionalista (Luiz Inácio Lula da Silva). Em um ambiente de expectativas macroeconômicas instáveis, o desempenho da formação bruta de capital fixo ficou praticamente estagnado.

(17) Serrano e Summa (2015) trabalharam com o comportamento do investimento desagregando os seus componentes. Os autores mostram que a queda mais acentuada se deu no componente "máquinas e equipamentos" que cresceu a uma taxa média de $12,3 \%$ no período $2004-10$ e $0,7 \%$ entre 2011 e 2014 . Os autores ainda argumentam que este componente é impulsionado quando os empresários entendem que haverá um crescimento da demanda efetiva. Sendo assim quando a expectativa é positiva, a tendência é que o investimento em máquina e equipamentos seja acentuado. Contudo, quando o ciclo de expectativa se reverte, a tendência é que o investimento desacelere mais rápido do que a própria demanda. 
Em consequência das políticas anticíclicas de estímulo à demanda agregada implementadas pelo governo federal entre o último trimestre de 2008 e o ano 2009 , a economia obteve um crescimento econômico em 2010 considerado surpreendente $(7,5 \%)$ e as taxas de crescimento da FBCF positivas foram restabelecidas, sendo o pico da série atingido no terceiro trimestre do ano de 2010. A recuperação observada em 2010 foi pontual, pois, mesmo que as taxas de crescimento do PIB e da FBCB tenham sido positivas até o ano de 2014, a tendência de ambas era de desaceleração desde 2011. Entre os anos de 2011 e 2014 o crescimento médio anual do PIB e da FBCF foram respectivamente de $2,4 \%$ e $2,3 \%$.

Vale ressaltar que o governo não assistiu inerte a derrocada da taxa de investimento. A fim de tentar estimular a retomada do investimento por parte do setor privado, políticas que visavam à redução dos custos e consequentemente elevação da margem de lucro foram implementadas. Pode-se destacar, conforme Serrano e Summa (2015), a redução da taxa de juros nominal cobrado pelo Banco Nacional de Desenvolvimento Econômico e Social (BNDES) para estimular novos empréstimos para investimento, a desvalorização da moeda para elevar a competitividade e a margem de lucro dos exportadores, a desoneração da folha de pagamentos de alguns setores e dos impostos que incidem sobre a importação de bens de capital. Por conta dessas intervenções foi possível observar taxas positivas de investimentos até 2014, mesmo em um cenário de desaceleração. A partir do ano de 2015 a tendência de desaceleração se acentua e a economia brasileira entra em recessão. Entre os anos de 2015 e 2016 todos os componentes da demanda agregada, com exceção das exportações, apresentaram taxas médias de crescimento negativas. $\mathrm{O}$ destaque recai sobre a performance da FBCF que apresentou um crescimento médio anual de $-12,0 \%$.

Em suma, a crise financeira internacional vem a interromper um breve ciclo expansivo da economia brasileira, e tornou mais estreito seu espaço de política. $\mathrm{O}$ 'círculo vicioso particular' da economia brasileira, conforme descrito por Kregel (op. cit.), aprofundou o seu processo de financeirização ao elevar os níveis de endividamento tanto público como privado. O cenário externo após a crise financeira internacional também é caracterizado pela alteração da política de crescimento chinesa ${ }^{18}$, a qual busca reorganizar o padrão de crescimento voltandose para o consumo interno e, conforme aponta Carneiro (2017), pela ameaça de mudança na política monetária Norte-Americana em meados de 2013.

(18) Vale observar também que a queda dos preços das commodities atingiu a dinâmica de crescimento da economia brasileira. O pico das exportações brasileiras para a China ocorreu em 2013 com o valor aproximado de 46 bilhões de dólares. Outra informação relevante para o Brasil foi o pico de investimento chinês no Brasil que sai de 13,9 bilhões de dólares em 2010 para 0,27 bilhões de dólares em 2015. 


\section{$4 \mathrm{O}$ financiamento do investimento e o comportamento das ENFs}

As relações financeiras envolvidas no financiamento do investimento em ativos de capital em economias modernas, como visto na seção 2, explicam as causas das reversões cíclicas. A economia brasileira a partir de 2015 claramente entrou em uma fase recessiva, cabendo, portanto, investigar como esta pode ser explicada por mudanças na dinâmica de acumulação de capital fixo. Por outro lado, um maior nível de endividamento por parte das ENFs é entendido como um sintoma do fenômeno da financeirização.

Relatório do Ipea (2013, p. 9), sobre o financiamento das corporações, mostra que um impulso à acumulação de capital em ativo fixo foi observado na economia brasileira através da expansão dos canais de financiamento disponíveis às empresas. O relatório aponta como as principais fontes para a acumulação de capital, uma ampla reserva de recursos próprios por parte das empresas; os desembolsos pelo BNDES no financiamento de longo prazo e o crescente acesso aos mercados financeiros internacionais. No que segue analisaremos estas fontes de financiamento assim como mostraremos evidência sobre mudanças na composição do lucro da indústria.

\subsection{Autofinanciamento: uma tendência de mudança}

O autofinanciamento como principal fonte de financiamento da acumulação de capital no país é reconhecido em diversos estudos (ver, por exemplo, Singh, 1995; Moreira; Puga, 2000; Almeida et al., 2013). Porém, Almeida et al. (2013, p. 40) constatam que desde a década de 1990 principalmente as grandes empresas brasileiras têm aumentado o seu nível de endividamento geral e de longo prazo, aproximando a estrutura de financiamento a um padrão com base no crédito.

Dados das Contas Nacionais mostram que de 2003 até 2007, em todos os anos, a capacidade de autofinanciamento das ENFs superou o gasto em investimento (tabela 2). A partir de 2008 a parcela de autofinanciamento situou-se abaixo do investimento mostrando que o padrão de financiamento das ENFs mudou.

Tabela 2

Autofinanciamento das empresas não financeiras ${ }^{1}$ (\%): 2000-2014

\begin{tabular}{l|l|l|l|l|l|l|l}
$\mathbf{2 0 0 0}$ & $\mathbf{2 0 0 1}$ & $\mathbf{2 0 0 2}$ & $\mathbf{2 0 0 3}$ & $\mathbf{2 0 0 4}$ & $\mathbf{2 0 0 5}$ & $\mathbf{2 0 0 6}$ & $\mathbf{2 0 0 7}$ \\
\hline 105,3 & 98,7 & 89,7 & 120,9 & 126,1 & 112,4 & 115,7 & 100,5 \\
\hline \multicolumn{2}{|l}{} \\
\hline $\mathbf{2 0 0 8}$ & $\mathbf{2 0 0 9}$ & $\mathbf{2 0 1 0}$ & $\mathbf{2 0 1 1}$ & $\mathbf{2 0 1 2}$ & $\mathbf{2 0 1 3}$ & $\mathbf{2 0 1 4}$ \\
\hline 96,6 & 99,1 & 76,7 & 78,4 & 77,2 & 86,3 & 97,8 \\
\hline
\end{tabular}

${ }^{1}$ Renda disponível sobre formação bruta de capital

Fonte: Contas Nacionais, Contas Econômicas Integradas (Ceis) - IBGE. Elaboração própria. 
Comparando a evolução da série da FBCF com a evolução do crédito às pessoas jurídicas (saldo das operações de crédito para pessoa jurídica considerando recursos livres mais recursos direcionados) podemos inferir sobre o momento de transição para ENFs quando, devido à retração na demanda agregada, o ônus da dívida aumenta relativamente ao total da receita. O Gráfico 2 mostra que os investimentos foram estimulados pela expansão do crédito até meados de $2013^{19}$. No entanto, a partir de 2013 observou-se um descolamento entre a taxa de crescimento das duas variáveis, com o crédito crescendo, notadamente, de forma mais acelerada.

Gráfico 2

Formação bruta de capital fixo e Operações de crédito para pessoa jurídica 2007-2016

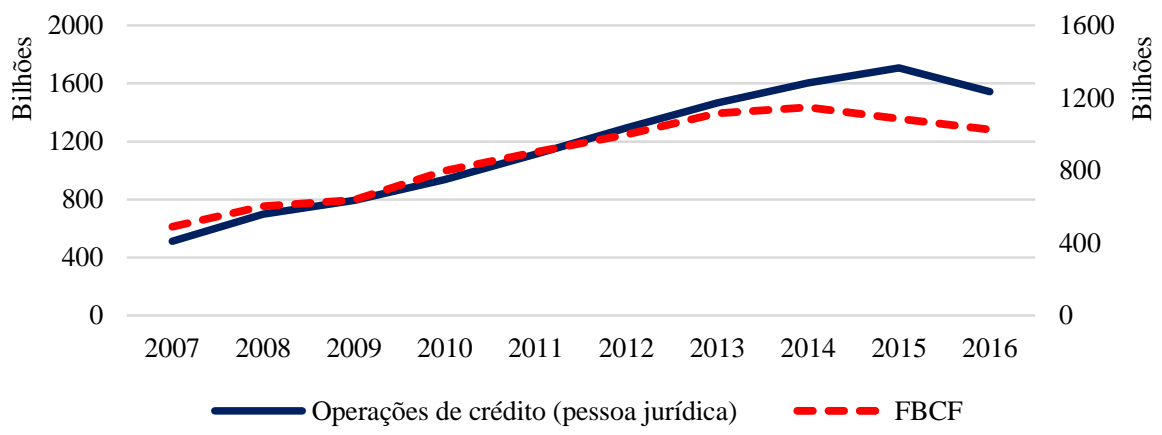

Fonte: Ipeadata e SCNT (IBGE). Elaboração própria.

$\mathrm{O}$ fato do crédito às empresas continuar aumentando enquanto o investimento inicia um processo de desaceleração com retração pode remeter ao início do aumento da fragilidade financeira exposta na seção 2. O Gráfico 2 busca identificar o momento crítico de mudança quando um número crescente de empresas veem quebradas suas expectativas de receita e se veem obrigadas a refinanciar suas dívidas em condições piores pois a taxa básica de juros (Selic) inicia uma trajetória de elevação a partir de 2013, chegando a 14,25\% ao ano em 2016 (após ter alcançado a menor taxa nominal dos últimos anos, 7,25\% ao ano em 2012).

Dois estudos recentes (Cemec, 2016; Rocca, 2016) também apontam na direção de estar havendo uma mudança no padrão de financiamento das empresas. Segundo os estudos, após 2010, as tendências das variáveis lucro líquido, investimento, leverage e retenção de lucros se alteram (Gráfico 3). O lucro líquido, a retenção de lucros e os investimentos passam a ter uma trajetória decrescente, que

(19) Melo e Rodrigues Júnior (1998), Ribeiro e Teixeira (2001) citados em Luporini e Alves (2010) demonstram econométricamente que a disponibilidade de crédito possui uma influência positiva no nível dos investimentos privados, sendo o crédito uma variável bastante relevante. 
se acelera a partir de 2013. Da mesma forma, a tendência de queda do lucro retido como parcela da formação bruta de capital das ENFs se acelera a partir de 2010 até se reverter em 2013.

Gráfico 3

Cias Abertas com Petrobras e Maiores Cias Fechadas: 2005-2015

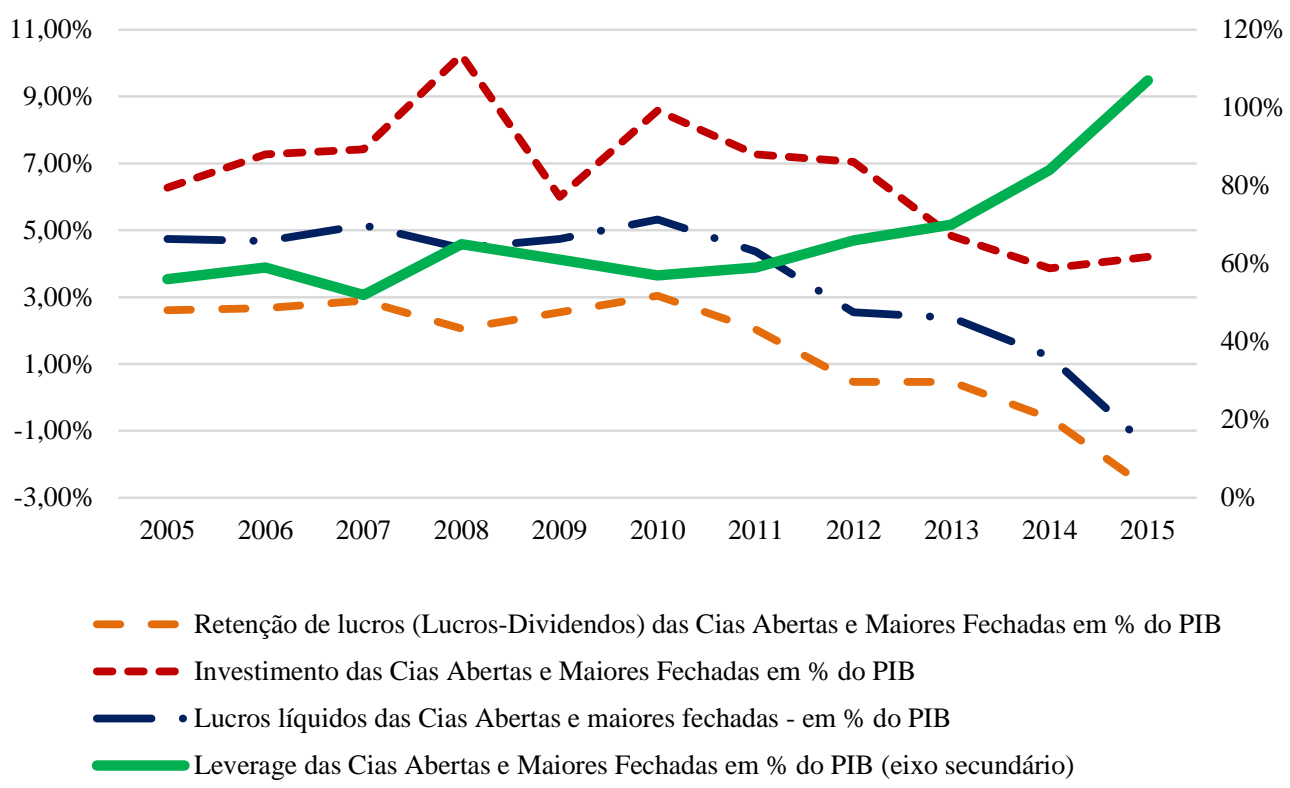

Fonte: Rocca (2016). Base de dados Cemec. Elaboração própria.

\subsection{Endividamento externo}

O aumento do índice de alavancagem e a queda da retenção de lucros também foi acompanhado de uma alteração na composição da dívida das ENFs. Essa alteração é caracterizada pelo aumento da importância da dívida em moeda estrangeira. Segundo dados do Banco Central do Brasil, do segundo trimestre de 2007 ao segundo trimestre de 2016 a dívida externa bruta das ENFs cresceu $142,62 \%$.

O estudo do Cemec (op. cit.) mostra que nas companhias abertas, sem a Petrobras, a participação da dívida em moeda estrangeira passa de 24,2\% em 2010 para 46,3\% no segundo trimestre de 2016 (Gráfico 4). Adicionando a Petrobras à análise, a dívida em moeda estrangeira passou de 32,7\% em 2010 para 60\% no segundo semestre de 2016. 
Composição da dívida das cias abertas não financeiras 2010-2016*

CIAs Abertas s/ Petrobras

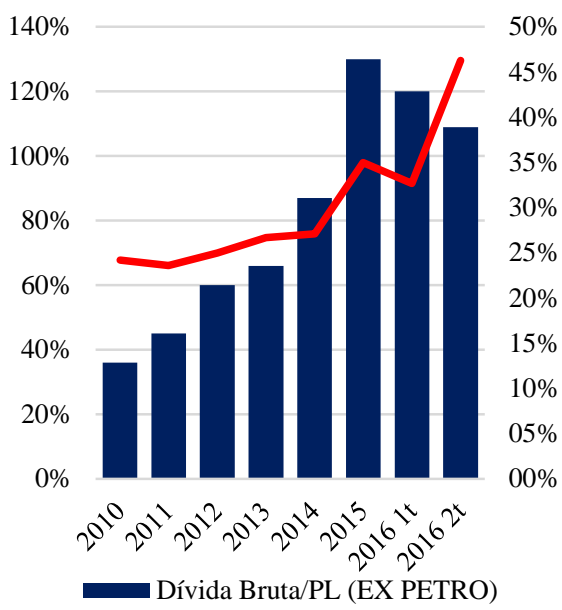

(*) Dados até o segundo trimestre de 2016.
CIAs Abertas c/ Petrobras

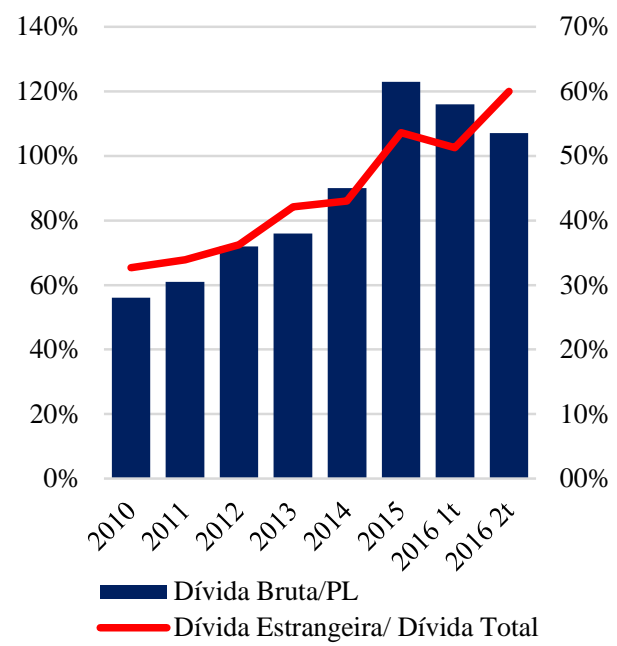

Fonte: Cemec 2016). Elaboração própria.

Ao mesmo tempo, a evolução dos desembolsos do BNDES também mostra uma mudança de tendência ao longo do período 2000-2014. Entre 2000 e 2013, os desembolsos totais do BNDES em termos nominais apresentaram tendência crescente, retirando o ano de 2011. A partir de 2014 a tendência se torna negativa e se aprofunda em 2015. Os desembolsos dos programas focados na compra de máquinas e equipamentos possuem o mesmo comportamento.

\subsection{Evolução do crédito doméstico: custo e racionamento}

A combinação de uma trajetória de endividamento crescente aliada a uma trajetória de lucros líquidos declinante contribui para que a postura de uma parte significativa das ENFs seja considerada especulativa ou Ponzi. O já referido estudo do Cemec (2016) sobre endividamento das empresas brasileiras mostra a existência de uma trajetória crescente do número de empresas que não é capaz de gerar caixa suficiente para cobrir as suas despesas financeiras. Segundo os dados observados, o total de empresas (companhias abertas e maiores companhias fechadas) nessa situação passou de 22,6\% em 2010 para 49,0\% em 2015 (Gráfico 5) ${ }^{20}$.

(20) Dados para as companhias fechadas e totais (que correspondem à somatória das companhias abertas e fechadas) até 2015. 
Gráfico 5

Porcentagem das empresas brasileiras com postura considerada Ponzi* $2010-2016$

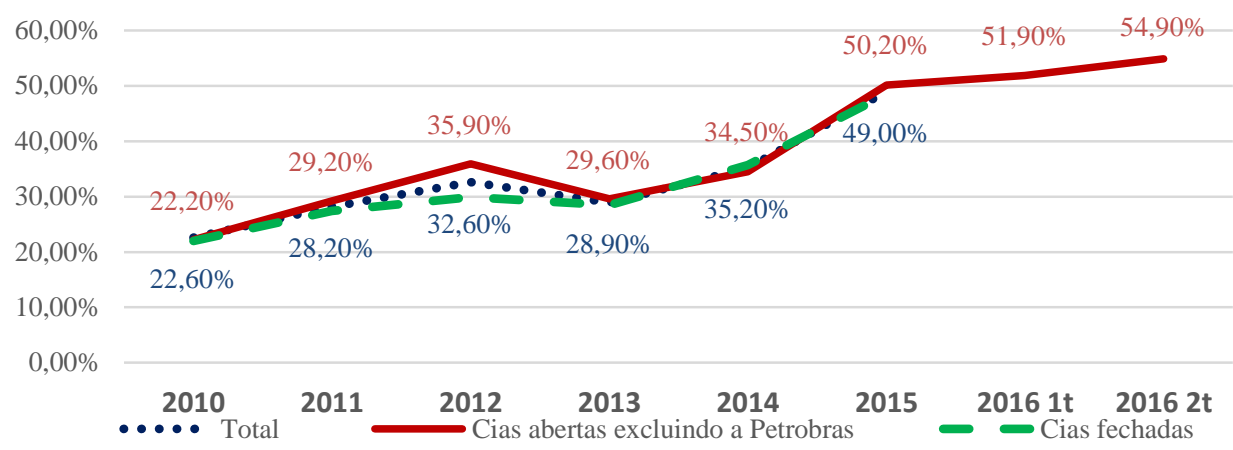

(*) O número de empresas que apresenta o indicador EBTIDA/Despesa Financeira $<1$

Fonte: Cemec (2016). Elaboração própria.

Como salientado anteriormente, quando uma economia possui um alto número de empresas com uma postura especulativa ou Ponzi, está sujeita a mais instabilidade financeira e é mais suscetível ao risco sistêmico e de contágio. Considerando a evolução da taxa de juros e do spread bancário (Gráfico 6), a economia brasileira a partir de 2014 entra em uma fase de maior fragilidade com a tendência de aumento de ambas as taxas.

Gráfico 6

Taxa de juros média (em \%) e spread médio (em p.p.): 2011-2016

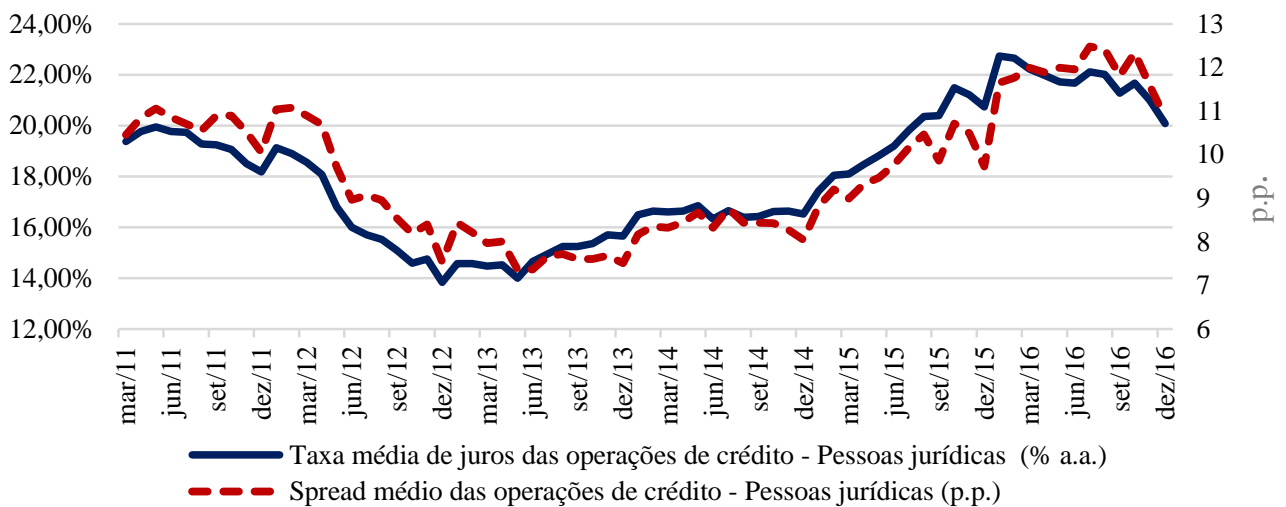

Fonte: BCB. Elaboração própria

Não só o custo do crédito aumenta, mas também a oferta fica mais racionada a partir de 2013. Dados do Banco Central do Brasil mostram que os saldos das operações de crédito a pessoas jurídicas tanto na rubrica recursos livres como na rubrica direcionados apresentam tendência declinante desde o ano de 2013. As concessões de crédito apresentam uma tendência semelhante desde o ano de 2014, essa tendência se aprofunda no terceiro trimestre de 2015. 
Complementamos a avaliação da evolução do endividamento das ENFs, com mais uma evidência do estudo do Cemec (op. cit., p. 15), observa-se que há uma redução da geração de caixa das ENFs em relação à receita operacional líquida (Rol) (calculada via a razão do Ebitda e a Rol). Esta razão passou de $20 \%$ da Rol em 2010, para $10 \%$ em $2015^{21}$. Segundo o estudo, esse resultado foi influenciado pelo aprofundamento da recessão econômica, que impactou negativamente as vendas $^{22}$, pela desvalorização cambial que impactou nos custos das empresas, pelo recrudescimento do processo inflacionário e pelo aumento das taxas de juros.

Por fim, o Gráfico 7 mostra o comportamento de um indicador proxy de fragilidade financeira para a indústria ${ }^{23}$. A interpretação do indicador é que quanto menor for, maior a fragilidade financeira do setor. Esse indicador corrobora que ocorreu um aumento da fragilidade financeira em 2008 por conta da crise financeira internacional ${ }^{24}$. Mostra ainda que a partir de 2010 o setor industrial encontra-se em uma posição de crescente fragilidade.

\section{Gráfico 7}

Indicador proxy da fragilidade financeira da indústria de transformação e extrativa- 2002-2014

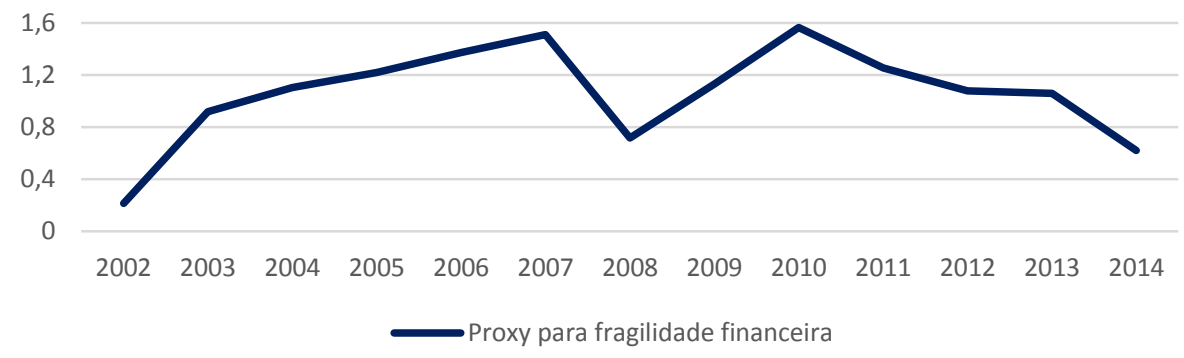

Fonte: Pesquisa Industrial Anual - PIA (IBGE). Elaboração própria.

Em suma, o expressivo aumento na relação FBCF/PIB a partir de meados dos anos 2000 foi resultado do clima de otimismo na economia diretamente relacionado ao boom dos preços de commodities e ao crescimento da demanda doméstica pela expansão do consumo e do investimento. Desta forma, configurouse um cenário propício para que o otimismo espontâneo fosse aflorado. Por

(21) Dados para as empresas abertas excluindo a Petrobras e para as maiores empresas fechadas.

(22) A utilização da capacidade instalada da indústria atingiu o menor valor em mais de vinte anos no ano de 2016 (77,2\%) (CNI em Ipeadata).

(23) A proxy para medir a fragilidade financeira do setor industrial foi calculada a partir da razão entre o lucro total das indústrias de transformação e extrativa, obtido pelo somatório das receitas menos o somatório das despesas, dividido pelo somatório das despesas não operacionais, mais os impostos e taxas.

(24) De Almeida et al (2016) salientam que embora nenhum setor esteja, plenamente, em posição Ponzi, é possível dizer que houve um processo de fragilização financeira após a crise financeira internacional. Destaca-se o setor industrial como o que mais elevou o número de empresas em posição Ponzi. O estudo mostra ainda que a piora da situação financeira das empresas analisadas inicia-se em 2012 e se agrava em 2013. 
consequência deste cenário favorável, as empresas recorreram ao mercado de crédito a fim de financiar seus investimentos produtivos, na confiança de que os excedentes gerados seriam suficientes para cobrir custos operacionais e financeiros. Contudo, a mudança de cenário externo, com impacto negativo sobre as expectativas empresariais, reverte o ciclo expansivo, deteriorando a situação financeira das empresas. É neste sentido que entendemos que a economia brasileira está passando pela fase descendente de um "ciclo minskyano". Tem-se claramente um momento de boom dos investimentos a partir de 2006, aumento do endividamento das empresas (o endividamento é pautado pela aversão ao risco dos empresários e, quanto menos avesso ao risco, maior as chances de assumir uma posição financeira especulativa ou Ponzi) seguido de uma quebra das expectativas de ganhos marcadamente a partir de 2013 e de retração da oferta de crédito.

\subsection{Lucros financeiros das ENFS}

Uma das características do processo de financeirização é a redistribuição de lucros do setor não-financeiro para o setor financeiro (Palley, 2013, p. 5). Dessa forma, a parcela dos lucros provenientes dos setores não-financeiros decairia em prol de um aumento da parcela dos lucros provenientes do setor financeiro. Por outro lado, o processo de financeirização poderia levar a uma mudança na própria composição dos lucros dos setores não-financeiros, de modo que o lucro não operacional aumentaria a sua participação no lucro total em decorrência de uma queda da participação do lucro operacional (ver por exemplo, Clévenot, 2006, p. 4). Ou seja, as empresas iriam compensar parte da retração das suas atividades tradicionais com o aumento da atividade financeira.

Considerando o peso das empresas financeiras na economia brasileira, observa-se uma pequena elevação da parcela de renda disponível bruta do setor financeiro no total da economia de 2,0\% em 2000 para 2,3\% em 2014. Vale observar ainda que o ligeiro aumento do peso do setor financeiro na estrutura produtiva da economia ocorre em um contexto de recuo acentuado do peso da indústria de transformação, o setor de atividade mais dinâmico, no total de valor adicionado. Em 2000 a indústria manufatureira contribuía com 15,3\% do total do valor adicionado a preços correntes, e em 2014 este percentual correspondia a 12,0\%. Outra maneira de constatar o aumento da importância do setor financeiro é no montante de juros pagos pela economia como um todo que em 2013 representou 33,3\% do PIB segundo as Contas Nacionais.

Em relação ao setor manufatureiro, através dos dados da Pesquisa Industrial Anual (PIA), podemos analisar como se comportou o lucro operacional e o lucro não operacional entre os anos de 1996 e 2014 (Gráfico 8).

O comportamento dessas variáveis apresenta trajetórias bem claras. Primeiramente, nota-se que o lucro não operacional supera o lucro operacional na maior parte do período analisado. É possível observar que o lucro não operacional 
possui uma tendência de crescimento até 2013, essa tendência possui uma quebra significativa em 2011, mesmo ano em que a taxa Selic real obteve a menor taxa do período $(3,9 \%)$. Por sua vez, a trajetória do lucro operacional é mais errática durante o período, de maneira que é possível distinguir apenas dois movimentos claramente: tendência crescente (2003-2007) e tendência decrescente (2012-2014).

Gráfico 8

Lucro operacional $^{1}$, Lucro não operacional ${ }^{2}$, Taxa Selic Real ${ }^{3}$ e Crescimento do PIB para a indústria de transformação - 1996-2014

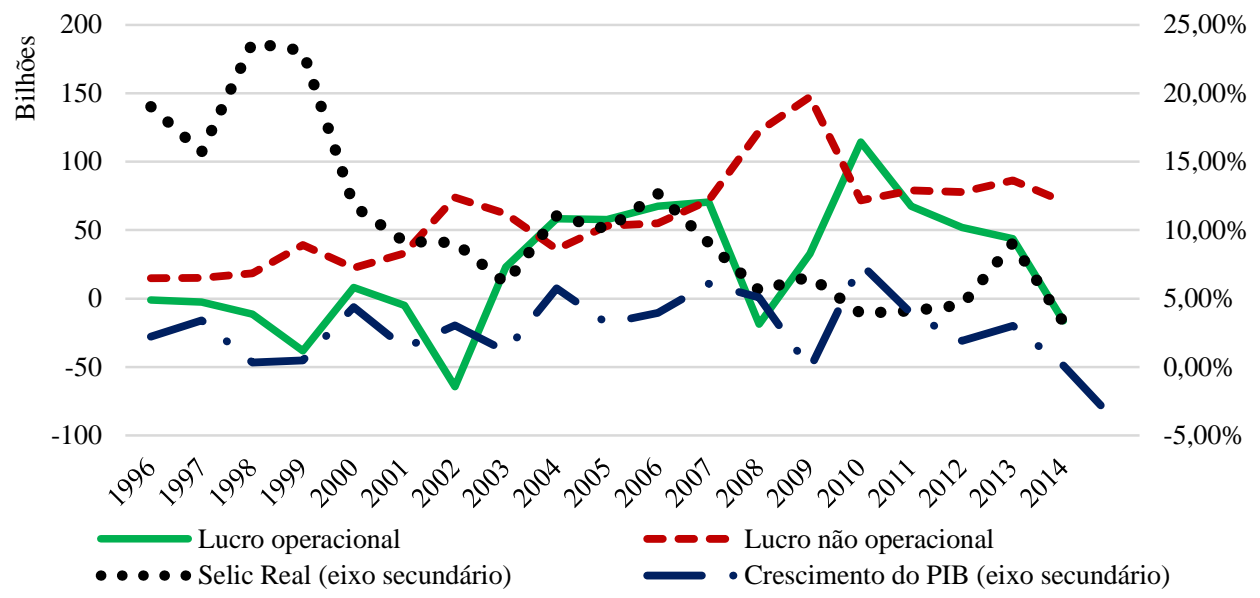

${ }^{1} \mathrm{O}$ lucro operacional foi calculado através da subtração da despesa operacional total da receita operacional total.

${ }^{2} \mathrm{O}$ lucro não operacional foi calculado através da subtração da despesa não operacional total da receita não operacional total.

${ }^{3}$ A taxa Selic real anual foi calculada através da média geométrica das taxas reais mensais acumuladas ao ano. O índice de inflação utilizado foi o IPCA.

Fonte: Pesquisa Industrial Anual (PIA) - IBGE. BCB (Selic). SCNT (PIB). Elaboração própria.

\section{Conclusão}

Como foi discutido neste trabalho, a crise financeira internacional de 2008 contribuiu para uma alteração na estratégia patrimonial das ENFs. No ciclo de expansão anterior à crise financeira internacional (2003-2008), as empresas brasileiras foram estimuladas pela expansão do comércio, pelo aumento da liquidez internacional, pela melhora nos termos de troca e também pela expansão do mercado interno. O aumento do investimento foi baseado em uma alteração no perfil do seu financiamento, de maneira que a participação dos meios de financiamento externo às empresas foi ampliada. Como consequência o nível de endividamento das empresas aumentou substancialmente nesse período. Após a crise financeira, há uma desaceleração do investimento, e o peso do endividamento das empresas aumenta. 
Desde o ano de 2010, segundo estudo do Cemec, a retenção de lucros e o lucro líquido das empresas são declinantes, enquanto o nível de endividamento e de alavancagem das mesmas são crescentes. Como resultado desse processo, dentre as companhias abertas e maiores companhias fechadas $49 \%$ delas não eram capazes de gerar o caixa suficiente para o pagamento das suas despesas financeiras no ano de 2015. Soma-se a essa conjuntura, o comportamento restritivo do setor bancário (aumento do spread bancário e da seletividade nas concessões de crédito) que contribui para o aprofundamento do ciclo de endividamento das empresas ao aumentar os custos de rolagem das dívidas.

Dado o aumento da alavancagem e da exposição cambial de um número significativo de empresas brasileiras observado nos últimos anos é possível caracterizar que essa parcela das empresas possui postura de financiamento Ponzi

Dentro do contexto apresentado neste artigo, a economia brasileira estaria enquadrada em uma fase descendente do ciclo minskyano. A saída desse ciclo depende da melhoria da condição financeira das ENFs, ou seja, depende da recuperação do cash flow das mesmas, que por sua vez depende da recuperação do nível da demanda agregada e da queda na taxa de juros reais.

Analisando o período atual da economia brasileira, a dificuldade na recuperação do dinamismo econômico nos últimos anos ${ }^{25}$ perpassa a dificuldade na recuperação do crescimento da formação bruta de capital que foi o principal eixo do crescimento observado no período de expansão anterior. Dada a atual política austeridade econômica do governo federal, e de grande parte dos governos regionais, a saída da recessão recai, única e exclusivamente, sobre a recuperação do investimento privado. Porém, nem a atual política macroeconômica, nem a configuração financeira das empresas contribuem para a consecução dessa estratégia. Soma-se a esse contexto a crise política, que se estende desde 2016, que aumenta a incerteza e a insegurança em relação ao governo em suas diferentes frentes.

\section{Bibliografia}

AGLIETTA, M. Shareholder value and corporate governance: some tricky questions. Economy and Society, v. 29, n. 1, p. 146-159, 2000.

ALMEIDA, J. S. G. de; NOVAIS, L. F.; ROCHA, M. A. A fragilização financeira das empresas não financeiras no Brasil pós-crise. Campinas: Unicamp. IE, set. 2016. (Texto para Discussão, n. 281).

(25) A desaceleração do crescimento da formação bruta de capital fixo (FBCF) se inicia no quarto trimestre do ano de 2010, salvo o período entre o terceiro trimestre de 2013 e o primeiro trimestre de 2014 no qual houve uma pequena aceleração no crescimento da FBCF (ver Gráfico 1). 
BIANCARELLI, A. M. A visão convencional sobre a abertura financeira e suas mutações recentes. Estudos Econômicos, v. 40, n. 4, p. 917-942, out./dez. 2010.

BIELSCHOWSKY, R.; MUSSI, C. El pensamiento desarrollista en Brasil: 19301964 y anotaciones sobre 1964-2005. In: CAVE, R. Brasil y Chile: una mirada hacia América Latina. Santiago de Chile: RIL Editores, 2006.

BONIZZI, B. Financialization in developing and emerging countries: a survey international. Journal of Political Economy, v. 42, n. 4, p. 83-107, 2013.

BOYER, R. Is a finance-led growth regime a viable alternative to fordism? A preliminary analysis. Economy and Society, v. 29, n. 1, p. 111-145, 2000.

BRUNO, M.; CAFFÉ, R. Indicadores macroeconômicos de financeirização: metodologia de construção e aplicação ao caso do Brasileiro. In: IBGE. Indicadores macroeconômicos de financeirização: metodologia de construção e aplicação ao caso do Brasil. Rio de Janeiro: IBGE, 2015.

BRUNO, M.; DIAWARA, H.; ARAUJO, E.; REIS, A. N.; RUBENS, M. Financeled growth regime no Brasil. Revista de Economia Política, v. 31, n. 5, p. 730-750, 2011.

CARNEIRO, R. Navegando a contravento (Uma reflexão sobre o experimento desenvolvimentista do Governo Dilma Rousseff). Campinas: Unicamp. IE, mar. 2017. (Texto para Discussão, n. 289).

CARNEIRO, R., Globalização financeira e inserção periférica. Economia $e$ Sociedade, v. 13, p. 57-92, 1999.

CEMEC. Endividamento das empresas brasileiras: metade das empresas não gera caixa para cobrir despesas financeiras em 2015/2016. Instituto IBMEC Mercados de Capitais, ago. 2016. (Nota Cemec, n. 6).

CLÉVENOT, M., Financiarisation, régime d'accumulation et mode de régulation. Peut-on appliquer le "modèle" américan à l'èconomie française? Tese-Université Paris-Nord - Paris XIII, 2006. p. 377.

ESPTEIN, G. (Ed.). Financialization and the world economy. Cheltenham: Edward Elgar, 2005.

GUTTMANN, R. Finance-led capitalism: shadow banking, re-regulation, and the future of global markets. New York: Palgrave Macmillan, 2016. p. 286.

HEIN, E. The macroeconomics of finance-dominated capitalism - and its crisis. Cheltenham: Edward Elgar Publishing, 2012. p. 232.

KARWOWSKI, E.; STOCKHAMMER, E. Financialisation in emerging economies: a systematic overview and comparison with Anglo-Saxon economies. Economic and Political Studies, v. 5, n. 1, p. 60-86, 2017.

KREGEL, J. The Brazilian crisis: from inertial inflation to fiscal fragility. Levy Economics Institute, 2000. (Economics Working Paper, n. 294).

LAZONICK, W.; O'SULLIVAN, M. Maximizing shareholder value: a new ideology for corporate governance. Economy and Society, v. 29, n. 1, p. 13-35, 2000. 
LUPORINI, V.; ALVES, J. Investimento privado: uma análise empírica para o Brasil. Economia e Sociedade, v. 19, n. 3, p. 449-475, 2010.

MINSKY, H. P. Stabilizing an unstable economy. New Haven: Yale University Press, 1986.

MINSKY, H. P. The financial instability hypothesis. Levy Economics Institute, 1992. (Working Paper, n. 74).

MOREIRA, M. M.; PUGA, F. P. Como a indústria financia o seu crescimento: uma análise do Brasil pós-plano Real. Rio de Janeiro: BNDES, out. 2000. (Texto para Discussão, n. 84).

ORHANGAZI, O. Financialisation and capital accumulation in the non-financial corporate sector: a Theoretical and empirical investigation on the US economy: 1973-2003. Cambridge Journal of Economics, v. 32, n. 6, p. 863-886, 2008.

PAINCEIRA, J. P. Developing countries in the era of financialisation: from deficit accumulation to reserve accumulation. Research on Money and Finance, School of Oriental and African Studies, 2009. (Texto para Discussão, n. 4).

PALLEY, T. Financialization: the economics of finance capital domination. New York: Palgrave Macmillan, 2013. p. 233.

PAULA, L. F. de. A economia brasileira em condições de instabilidade financeira. Disponível em: http://www.luizfernandodepaula.com.br/ups/economia-brasileiraem-condicoes-de-instabilidade-financeira-01.pdf. Acesso em: 10 jan. 2017.

POWELL, J. Subordinate financialisation: a study of Mexico and its non-financial corporations. Tese (Doutorado)-London: SOAS University of London, 2013. p. 354.

ROCCA, C. A. Desafios da retomada do investimento privado: a necessidade de uma nova estratégia de crescimento. Apresentação feita no IBRE-FGV. Rio de Janeiro, out. 2016.

SERRANO, F.; SUMMA, R. Demanda agregada e a desaceleração do crescimento econômico brasileiro de 2011 a 2014. Center for Economic and Policy Research, 2015.

SICSÚ, J. Rumos da liberalização financeira brasileira. Brazilian Journal of Political Economy (Revista de Economia Política), v. 26, n. 3, p. 364-380, 2006.

SINGH, A. Corporate financial patterns in industrializing economies: a comparative international study. International Finance Corporation technical paper, Washington, DC, n. 2, 1995. (IFC Working Paper Series).

STOCKHAMMER, E. Shareholder value orientation and the investment-profit puzzle. Journal of Post Keynesian Economics, n. 28, p. 193-215, 2005-2006.

STOCKHAMMER, E. Financialization and the slowdown of accumulation. Cambridge Journal of Economics, v. 28, n. 5, p. 719-741, 2004. 